\title{
PKN2 Regulates the Survival of PC12 Cells by Activating the AKT/mTOR Pathway
}

\author{
L. WING, G. DING, J. XUE AND YU-WI ZHANG ${ }^{1 *}$ \\ Department of Orthopaedics, The Yijishan Hospital of Wannan Medical College, Anhui, People's Republic of China, \\ ${ }^{1}$ Department of Anatomy of Wannan Medical College, Anhui, People's Republic of China
}

\section{Wang et al.: PKN2 Activating the AKT/mTOR Pathway}

\begin{abstract}
Neurons are prone to apoptosis after peripheral nerve damage and the effect of repair is not satisfactory yet, so it is important to find new molecular targets for treatment. Previous studies demonstrated that the downstream of AKT signalling pathway is highly related to neuro apoptosis and axon regeneration and this study showed that protein kinase $\mathrm{N}$, a kind of serine/threonine-protein kinase, could promote the phosphorylation levels of AKT and mTOR. However, whether protein kinase N2 plays an important role in peripheral nerve apoptosis and regeneration and its detailed molecular mechanisms is still unknown. In preliminary experiments it was observed that protein kinase $\mathrm{N} 2$ inhibited apoptosis and promoted the growth for PC12 cells. It was observed that AKT/mTOR signalling pathway is activated in expression of protein kinase $\mathrm{N} 2$ cells. It will provide theoretical evidence for the treatment of peripheral nerve damage.
\end{abstract}

Key words: Protein kinase N2 (PKN2), AKT/mTOR, PC12

AKT signalling pathway is one of the important signalling pathways mediating regeneration of peripheral nerves ${ }^{[1,2]}$. As a signalling pathway with multiple phosphorylation and regulatory sites, and a wide range of biological functions, AKT plays a pivotal role in the regulation of the nervous system ${ }^{[3,4]}$. According to the literature, the mRNA expression profile of damaged motor neurons showed that the survival and regeneration of neurons were most likely related to ERK1 and AKT signalling pathways and the expression of their downstream genes was most obvious $^{[5]}$. The experimental results of neonatal sublingual nerve transection further showed that PI3K/ AKT signalling pathway plays an important role in the process of apoptosis and regeneration of motor neurons, even more important than Ras-ERK1 pathway ${ }^{[6]}$. The active downstream of the AKT has an important target is $\mathrm{mTOR}^{[6,7]}$. It has been suggested that the reduction of mTOR is related to the decline of central nervous system regeneration, mTOR can mediate neural repair and regeneration after central nervous system injury ${ }^{[8,9]}$. In addition, studies have shown that activation of mTOR by knocking out TCS2 gene up-regulates axonal regeneration of key gene GAP-43, thereby promoting DRG axonal regeneration after dorsal root ganglion injury ${ }^{[6]}$. Simultaneously, mTOR pathway can increase the number of endogenous neural stem cells, induce axonal growth, and promote the recovery of motor function in rats with spinal cord injury ${ }^{[10-14]}$. Therefore, the study of AKT/mTOR signalling pathway provides a theoretical basis and a molecular target for overcoming neuronal apoptosis and inducing axonal regeneration, which has important clinical significance.

Protein kinase N2 (PKN2) is a serine/threonine protein kinase $^{[14]}$. The PKN family is widely distributed in the cell membrane and cytoplasm, which has the kinase activity region at the C-terminal. PKN family include PKN1, $\mathrm{PKN} 2, \mathrm{PKN} 3$, in the $\mathrm{C}$-side kinase region has great similarity, but its distribution, function and regulation are very different. It has been reported that PKN family members act on different phosphatidylinositol and fatty acids and respond to different stimuli. PKN1-2 is widely distributed in eukaryotic tissues and PKN3 is mainly distributed in the muscle, liver and epithelial tissue. This study found that PKN1 is involved in the formation of cytoskeleton and neural cell differentiation with neuroprotective effects, the imbalance can lead to neuropathic occurrence, such as muscle atrophy and Alzheimer's disease ${ }^{[11]}$. The latest study found that PKN2 to promoted mouse embryonic development and neural crest migration, which is the key step of nerve regeneration and nerve development. Studies have 
shown that PKN2 can bind with tyrosine phosphatase via binding of PDZ domain and PKN2 also has SH3 domain, which is a potential effector of Rho signaling pathway ${ }^{[12]}$. PKN2 has kinase activity, phosphorylates $\mathrm{HCV}$ viral RNA polymerase and inhibits PKN2 down regulation of polymerase phosphorylation levels, thereby inhibiting $\mathrm{HCV}$ replication ${ }^{[13]}$. However, whether PKN2 regulates neuronal apoptosis and peripheral nerve regeneration is unknown.

Differentiated PC1 2 cells, a rat neuronal cell line derived from a pheochromocytoma cells (Shanghai Cellular Institute of China Scientific Academy, Shanghai, China), were maintained on cell culture flasks in Dulbecco's modified Eagle's medium (DMEM, high glucose, Gibco, USA) supplemented with $10 \%$ heat-inactivated horse serum, $5 \%$ fetal bovine serum, antibiotics $(100 \mathrm{U} / \mathrm{ml}$ penicillin $\mathrm{A}$ and $100 \mathrm{U} / \mathrm{ml}$ streptomycin, Gibco, USA) at $37^{\circ}$ under a humidified atmosphere of $5 \% \mathrm{CO}_{2}$ and $95 \%$ air, till reaching $70-80 \%$ confluence in $20 \times 100 \mathrm{~mm}$ collagen-coated culture dishes. As adding antibiotics to the medium during transfection reduces transfection efficiency, immediately before the siRNAs transfection, the PC 12 cells were plated in six plates with $2 \mathrm{ml}$ of growth medium without antibiotics.

The working concentration of the siRNAs was set as $100 \mathrm{nM}$ and made by diluting $20 \mu 110 \mu \mathrm{MPKN} 2$ siRNAin $180 \mu 1$ Opti-MEM I reduced serum medium (Invitrogen, Carlsbad, CA, USA) without serum according to the vendor's recommendation. The LipofectamineTM2000 yransfection reagents $(5 \mu 1$, Invitrogen, Carlsbad, CA, USA) were used for the transfection of siRNAs into PC12 cells, which was gently mixed and diluted in $250 \mu 1$ Opti-MEM I reduced serum medium and incubated for $5 \mathrm{~min}$. Immediately before the transfection procedures, the siRNAs were incubated with the diluted Lipofectamine 2000 for $20 \mathrm{~min}$ at room temperature, then the siRNA-Lipofectamine 2000 complex was added to each cell wells according to vendor's protocol. The treated PC12 cells were incubated at $37^{\circ}$ in a $\mathrm{CO}_{2}$ incubator with the transfection medium changed after $6 \mathrm{~h}$.

The cell pellets were scraped down and the protein extract was isolated using a RIPA buffer (Santa Cruz Biotechnologies, Santa Cruz, CA). The protein concentration was measured using the BCA method with a Bio-Rad protein assay reagent (Bio-Rad, Hercules, CA). For western blotting, samples (20 mg protein/ lane) were separated on $12 \%$ sodium dodecyl sulphatepolyacrylamide gel electrophoresis and transferred to polyvinylidene difluoride membranes (Pall, USA). To detect P-AKT protein and $\mathrm{p}-\mathrm{MTOR}$ protein, the membranes were blocked with $5 \%$ non-fat dry milk in Tris-buffered saline containing $0.1 \%$ Tween-20 at room temperature for $2 \mathrm{~h}$ and then incubated with the antiP-AKT antibody (diluted 1:1000, Santa Cruz Biotechnologies, Santa Cruz, CA) or with antiAKT antibody (diluted 1:1000, Santa Cruz Biotechnologies, Santa Cruz, CA) and antiP-mTOR antibody (diluted 1:1000, Cell Signalling, USA) overnight at $4^{\circ}$. After washing and incubating for $2 \mathrm{~h}$ at room temperature with a secondary antibody conjugated with horseradish peroxidase (diluted 1:4000, Amersham Biosciences, Piscataway, NJ), the blots were washed and developed by chemiluminescence according to the manufacturer's protocol (Super-Signal West Pico Chemiluminescence Substrate, Pierce). Blots were exposed to X-ray film (Fuji Film, Japan), and the intensity was quantified for both bands. The relative level of protein in the different lanes was compared by analysing scanned images using the NIH IMAGE program. All studies were performed a minimum of 3 times using independent cultures.

The data were collected by investigators blinded to the treatment. SPSS18.0 statistical software was used for data analyses. The data were statistically analysed by one-way analysis of variance as well as Bonferroni post hoc multiple comparison test. Data were expressed as mean \pm SD. Statistical significance was set at $\mathrm{p}<0.05$.

The stable PC12 cell lines were established with either high expression or silent expression (RNAi) PKN2. The morphology of cells was observed and photographed under microscope and the neurite outgrowth and soma enlargement was analysed by Image-Pro plus 6.0. The results represented that compared to the vector and RNAi-vector groups, high expression of PKN2 significantly promoted the neurite outgrowth and soma enlargement of PC12 cells ( $<<0.05$ ), while the RNAiPKN2 inhibited growth and cell enlargement $(p<0.05)$.

The influence of PKN2 to the AKT signal pathway was further studied and the downstream pathway mTOR. The ratio of p-AKT and p-mTOR in cultured PC12 cell were detected by western blot analysis, which was treated with either PKN2 or PKN2-RNAi. The result showed that, compared to the vector and RNAi-vector groups, high expression of PKN2 significantly promoted the levels of $\mathrm{p}$-AKT and $\mathrm{p}-\mathrm{mTOR}(\mathrm{p}<0.05)$, while after PKN2-RNAi treatment, $\mathrm{p}$-AKT and p-mTOR levels were similar to those in the Vector group. That means, the expression levels of P-AKT and P-mTOR were 
elevated in cells expressing PKN2, while the expression levels of P-AKT and P-mTOR were decreased in silent PKN2 cells (fig. 1).

When an external signal arrived, PI3K is activated to produce a second messenger PIP3 on the plasma membrane and PIP3 binds to the signal protein Akt and PDK1 containing the PH domain in the cell, causing PDK1 to phosphorylate the Thr308 of the Akt protein, leading to activation of $\mathrm{AKT}^{[14]}$. PDK1 is a serine/ threonine kinase that contains a C-terminal $\mathrm{PH}$ domain with multiple serine phosphorylation sites. At present, it has been reported that the autophosphorylation of Ser241 is necessary for the activity of PDK $1^{[15]}$. In addition, AKT can also be activated by PDK2 phosphorylation of its Ser473 ${ }^{[16]}$. The activity of the PI3K-AKT signalling pathway by lipid phosphatase PTEN and SHIP negative, these were different from PIP3 3 and 5 removal of phosphoric acid and transformed into $\mathrm{PI}(4,5) \mathrm{P} 2$ and $\mathrm{PI}(3,4) \mathrm{P} 2$ degradation. The activity of the PI3K-AKT signaling pathway is regulated by the phosphoryl phosphatase PTEN and SHIP, which are converted to $\mathrm{PI}(4,5) \mathrm{P} 2$ and $\mathrm{PI}(3,4)$ $\mathrm{P} 2$ by removing the phosphoric acid from 3 ' and 5 ' of
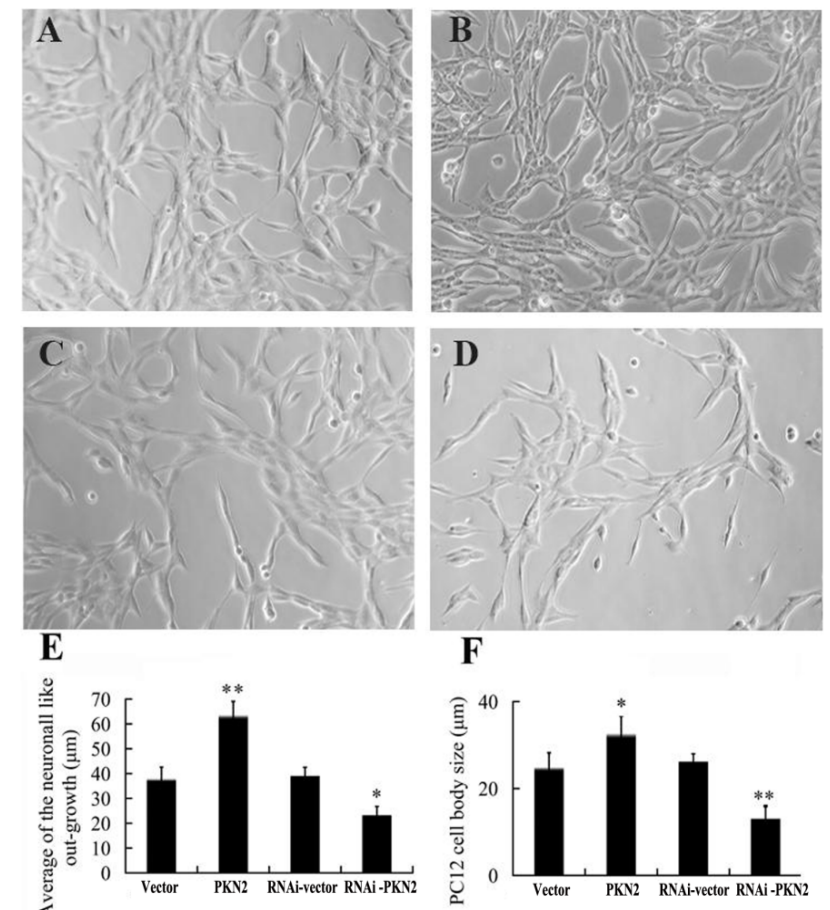

Fig. 1: Cell morphology images and cell axon length and cell size of PC12-Vector cells

A-D: the images of the morphology of cells under microscope: PC12-Vector cells (A), PC12-PKN2 cells (B), PC12-RNAi-Vector cells (C), PC12-RNAi cells (D)E-F: the cell axon length and cell size were measured, and the results showed that high expression of PKN2 promoted neurite growth and soma enlargement $(* p<0.05)$, while inhibition of PKN2 inhibited neurite growth and cell enlargement (* $p<0.05)$

Special Issue 3, 2020

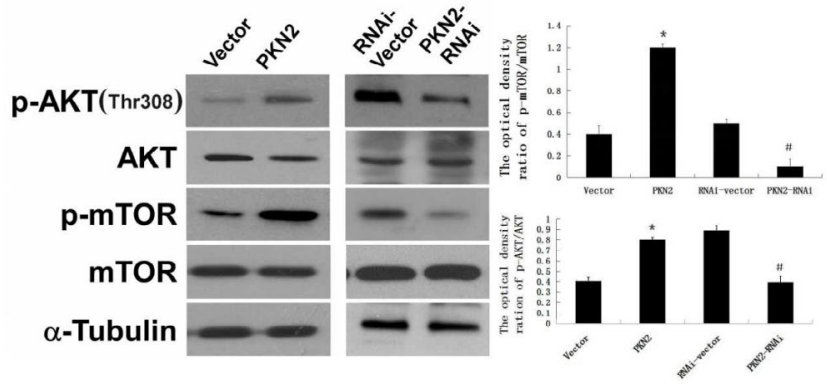

Fig. 2: Protein expression levels

The images of the protein expression are displayed. Statistical analysis showed that the levels of p-AKT and p-mTOR in the Vector group were significantly lower than in the PKN2 group. However, after RNAi treatment, p-AKT and p-mTOR levels were similar to those in the Vector group. ${ }^{*} p<0.05$, compared with Vector group; \#p<0.05, compared with PKN2 group

PIP3 and degradation ${ }^{[17,18]}$. After activation of mTOR, phosphorylated ribosomal protein P70S6 kinase and $4 \mathrm{E}$ binding protein-1 (4E-BP1) can regulate protein synthesis and cell growth. Phosphorylated p70S6K, a phosphorylated ribosomal protein $\mathrm{S} 6$, initiates a series of mRNA transcripts related to axon growth ${ }^{[8]}$. While 4E-BP1 can inhibit protein synthesis, phosphorylation of 4E-BP1 after its activity decreased, reducing its ability to inhibit protein synthesis, thereby promoting axon extension ${ }^{[19]}$. Therefore, AKT acts as a bridge molecule linking extracellular signals with cellular responses and plays an important regulatory role in the regeneration of peripheral nerves under the influence of a series of upstream signalling molecules acting on the downstream pathway (fig. 2). In the study of neuronal apoptosis, it was found that $\mathrm{NO}$ can inhibit the apoptosis of cerebellar granule neurons and inhibit nitric oxide synthase activity downstream of AKT NOS can promote the apoptosis of cerebellar granule neurons, and found that NO play a neuroprotective role through the AKT signal pathway. In the cultured neurons, the expression of the protein of the nNOS gene has a certain temporal characteristic. After knocking out the nNOS gene, the cell viability and number of the cultured neurons were observed. The results showed that compared with the control group. After the knocking out the nNOS gene, the viability of cultured neurons and the number of neurons decreased significantly. The activity of neurons increased when exogenous sodium nitroprusside was added to SNP. On the basis of this, the applicant further studied the effect of AKT signaling pathway on neuronal apoptosis and regeneration. It was found that PKN2 activated AKT/mTOR signaling pathway, promoted the phosphorylation of AKT Thr308 and increased the phosphorylation level of $\mathrm{mTOR}^{[20,21]}$. 


\section{Acknowledgements:}

Natural Science Foundation of Anhui Province (1708085QH209). "Peak" cultivation program of scientific research capacity of Yijishan Hospital (GF2019G16).

\section{Conflict of interest:}

The authors declare that they have no conflict of interest.

\section{REFERENCES}

1. Abe N, Borson SH, Gambello MJ, Wang F, Cavalli V. Mammalian target of rapamycin (mTOR) activation increases axonal growth capacity of injured peripheral nerves. J Biol Chem 2010;285:28034-43.

2. Boudewijn MT, Coffer PJ. Protein kinase B (c-Akt) in phosphatidylinositol-3-OH kinase signal transduction. Nature 1995;376:599-602.

3. Casamayor A, Morrice Na, Alessi D. Phosphorylation of Ser-241 is essential for the activity of 3-phosphoinositidedependent protein kinase-1: identification of five sites of phosphorylation in vivo. Biochem J 1999;342:287-92.

4. Chen CH, Sung CS, Huang SY, Feng CW, Hung HC, Yang $\mathrm{SN}$, et al. The role of the PI3K/Akt/mTOR pathway in glial scar formation following spinal cord injury. Exp Neurol 2016;278:27-41.

5. Christie KJ, Webber CA, Martinez JA, Singh B, Zochodne DW. PTEN inhibition to facilitate intrinsic regenerative outgrowth of adult peripheral axons. J Neurosci 2010;30:9306-15.

6. Christie KJ, Zochodne D. Peripheral axon regrowth: New molecular approaches. Neurosci 2013;240:310-24.

7. Han SH, Kim SJ, Kim EJ, Kim TE, Moon JS, Kim GW, et al. Phosphorylation of hepatitis C virus RNA polymerases ser29 and ser 42 by protein kinase C-related kinase 2 regulates viral RNA replication. J Virol 2014;88:11240-52.

8. Kalinski AL, Sachdeva R, Gomes C, Lee SJ, Shah Z, Houle $\mathrm{JD}$, et al. mRNAs and protein synthetic machinery localize into regenerating spinal cord axons when they are provided a substrate that supports growth. J Neurosci 2015;35:10357-70.

9. Kaplan DR, Miller FD. Signal transduction by the neutrophin receptors. Curr Opin Cell Biol 1997;9:213-21.

10. King D, Yeomanson D, Bryant HE. PI3King the lock: Targeting the PI3K/Akt/mTOR pathway as a novel therapeutic strategy in neuroblastoma. J Pediat Hematol 2015;37:245-51.
11. Manning BD, Cantley LC. AKT/PKB signaling: Navigating downstream. Cell 2007;129:1261-74.

12. Namikawa K, Honma M, Abe K, Takeda M, Mansur K, Obata $\mathrm{T}$, et al. Akt/protein kinase B prevents injury-induced motoneuron death and accelerates axonal regeneration. J Neurosci 2000;20:2875-86.

13. Pettmann B, Henderson CE. Neuronal cell death. Neuron 1998;20:633-47.

14. Quétier I, Marshall JJ, Spencer-Dene B, Lachmann S, Casamassima A, Franco C, et al. Knockout of the PKN family of Rho effector kinases reveals a non-redundant role for PKN2 in developmental mesoderm expansion. Cell Re 2016;14:4408.

15. Schmidt A, Durgan J, Magalhaes A, Hall A. Rho GTPases regulate PRK2/PKN2 to control entry into mitosis and exit from cytokinesis. The EMBO journal 2007;26:1624-36.

16. Sun Z, Hu L, Wen Y, Chen K, Sun Z, Yue H, et al. Adenosine triphosphate promotes locomotor recovery after spinal cord injury by activating mammalian target of rapamycin pathway in rats. Neural Regen Res 2013;8:101.

17. Thauerer B, Zur Nedden S, Baier-Bitterlich G. Protein Kinase C-Related Kinase (PKN/PRK). Potential key-role for PKN1 in protection of hypoxic neurons. Curr Neuropharmacol 2014;12:213-8.

18. Walker CL, Walker MJ, Liu NK, Risberg EC, Gao X, Chen $\mathrm{J}$, et al. Systemic bisperoxovanadium activates Akt/mTOR, reduces autophagy, and enhances recovery following cervical spinal cord injury. PLoS One 2012;7-1.

19. Yang $\mathrm{H}$, Guan L, Li S, Jiang Y, Xiong $\mathrm{N}$, Li L, et al. Mechanosensitive caveolin-1 activation-induced PI3K/Akt/ mTOR signaling pathway promotes breast cancer motility, invadopodia form. Oncotarget 2016;7(13):16227-47.

20. Zeng H, Yang K, Cloer C, Neale G, Vogel P, Chi H. mTORC1 couples immune signals and metabolic programming to establish T reg-cell function. Nature 2013;499:485-90.

21. Zhang Z, Zhang G, Xu X, Su W, Yu B. mTOR-rictor is the Ser 473 kinase for AKT1 in mouse one-cell stage embryos. Mol Cell Biochem 2012;361:249-57.

This is an open access article distributed under the terms of the Creative Commons Attribution-NonCommercial-ShareAlike 3.0 License, which allows others to remix, tweak, and build upon the work non-commercially, as long as the author is credited and the new creations are licensed under the identical terms

This article was originally published in a special issue, "Biomedical research applications in Pharmaceutical Sciences" Indian JJ Pharm Sci 2020:82(2)Spl issue3;8-11 